\title{
The adsorption of ethylene on the (100) surfaces of platinum, palladium and nickel: a DFT study
}

\author{
C.G.P.M. Bernardo, J.A.N.F. Gomes* \\ CEQUP/Departamento de Química, Faculdade de Ciências, Universidade do Porto, Rua do Campo Alegre, 687, 4150 Porto, Portugal
}

Received 11 September 2000; revised 24 November 2000; accepted 27 November 2000

\begin{abstract}
The density functional theory and the cluster model approach have been used to study the adsorption of the ethylene molecule on the (100) surfaces of platinum, palladium and nickel. For each metal surface, two adsorption sites have been considered: the atop site $(\pi)$ and the bridge site (di- $\sigma)$. For each case, optimized geometries, adsorption energies and vibrational wavenumbers have been calculated. The results show that ethylene adsorbs strongly on the three metal surfaces. Upon adsorption, the degree of distortion of the ethylene molecule (relative to its gas phase geometry), as well as the binding strength to the metal surface increases in the order $\mathrm{Pd}<\mathrm{Ni}<\mathrm{Pt}$. On the three metal surfaces the di- $\sigma$ adsorption mode is the preferred one. There is a good general agreement between the calculated results and the available experimental data. () 2001 Elsevier Science B.V. All rights reserved.
\end{abstract}

Keywords: Chemisorption; Clusters; Density functional calculations; Single crystal surfaces; Vibrations of adsorbed molecules

\section{Introduction}

The exact knowledge of the adsorption mode of the ethylene molecule on transition-metal surfaces is of importance for the understanding of catalytic reactions involving this small olefin. For this reason, in the last two decades, numerous experimental studies of the adsorption of ethylene on a variety of transitionmetal surfaces have been performed. These studies have led to the conclusion that at low temperatures ( $\cong 100 \mathrm{~K}$ ), the ethylene molecule adsorbs molecularly on the transition-metal single crystal surfaces in one of the following two ways: as a di- $\sigma$ complex or as a $\pi$-coordinated complex. In the di- $\sigma$ adsorption mode the ethylene molecule interacts with two metal

\footnotetext{
* Corresponding author. Tel.: +351-22-6073572; fax: +351-226098736.

E-mail address: jfgomes@ reit.up.pt (J.A.N.F. Gomes).
}

atoms and in the $\pi$ adsorption mode the ethylene molecule interacts with a single metal atom. The di$\sigma$ bonding is typified by the low temperature adsorption of $\mathrm{C}_{2} \mathrm{H}_{4}$ on $\mathrm{Pt}(111)$, whereas the $\pi$ bonding is typified by the low temperature adsorption of $\mathrm{C}_{2} \mathrm{H}_{4}$ on $\operatorname{Pd}(110)$. Experimentally, it is known that the two modes of binding are competitive on some metal surfaces.

The metals of group $10(\mathrm{Ni}, \mathrm{Pd}$ and $\mathrm{Pt})$ are very important catalysts in a large variety of chemical reactions such as hydrogenations/dehydrogenations, isomerizations and total oxidations. For this reason, numerous studies of the adsorption of ethylene on the surfaces of these transition-metals have been performed during the last decades. Considering the order of these elements down the group, for a given adsorbate a gradual change of the adsorbate-surface interaction, might be expected to follow the order $\mathrm{Ni} \rightarrow \mathrm{Pd} \rightarrow \mathrm{Pt}$. However, experimentally this is not 
observed. For example, for a given olefin the ease of hydrogenation over metal catalysts decreases in the order $\mathrm{Pd}>\mathrm{Pt}>\mathrm{Ni}$ and the ease of isomerization tends to decrease in the order $\mathrm{Pd}>\mathrm{Ni}>\mathrm{Pt}$. From these data it is clear that there are significant differences in the interaction of olefins with these metal surfaces. These differences served as a motivation for our present study of the adsorption of ethylene on Pt, Pd and Ni surfaces.

While the adsorption of ethylene on the (111) and (110) surfaces of platinum, palladium and nickel has already been extensively studied both by experimental [1-13] and by theoretical $[9,14-19]$ techniques, the adsorption on the corresponding (100) crystalographic surfaces has received considerably less attention [20-27]. Even so, some experimental studies have been performed on the ethylene adsorption on platinum (100) [20,21], palladium (100) [22,23] and nickel (100) [24-26] clean surfaces. In these studies, several experimental techniques have been used such as electron energy loss spectroscopy (EELS) [20,25], high-resolution electron energy loss spectroscopy (HREELS) [22-24], near-edge X-ray absorption fine structure spectroscopy (NEXAFS) [26], laser-induced desorption (LID) [24], temperature-programmed desorption (TPD) [24] and temperature-programmed reaction spectroscopy (TPRS) $[22,23]$. With respect to the theoretical studies of the adsorption of ethylene on the (100) surfaces of these metals, only one study [27] of the system $\mathrm{C}_{2} \mathrm{H}_{4} / \mathrm{Ni}(100)$ was found in the literature. In this theoretical study, $\mathrm{Xu}$ et al. [27] used the $\mathrm{X} \alpha$ method to evaluate chemisorption properties.

Although the type of bonding differs depending on the electronic and geometric structure of the surface, all studies to date conclude that, for low adsorbate coverages, the CC bond in adsorbed ethylene lies parallel to the surface. In all cases, the main interaction with the metal surface is through the electrons in the CC bond, causing an elongation of the carboncarbon bond which is accompanied by a bending of the hydrogens away from the surface. This type of bonding is commonly described by the DewarChatt-Duncanson model $[28,29]$ originally proposed to explain ethylene coordination in organometallic complexes. According to this model, the filled ethylene $\pi$-orbital donates electron density into an empty metal orbital, and the empty antibonding $\left(\pi^{*}\right)$ molecular orbital of ethylene accepts electron density from the filled metal orbitals. These donations and backdonations of electron density cause the ethylene molecule to rehybridize from $\mathrm{sp}^{2}$ to somewhere between $\mathrm{sp}^{2}$ and $\mathrm{sp}^{3}$. Experimentally, the measurement of the vibrational frequency corresponding to the $\nu_{2}(\mathrm{CC})$ stretching mode has been, perhaps, the most straightforward method for determining the state of hybridization of the adsorbed molecule, due to the high sensitivity of the CC stretching frequency to the hybridized state of the two carbon atoms. For example, $\nu(\mathrm{CC})$ is $1623 \mathrm{~cm}^{-1}$ for gaseous $\mathrm{C}_{2} \mathrm{H}_{4}$ and $993 \mathrm{~cm}^{-1}$ for gaseous $\mathrm{C}_{2} \mathrm{H}_{6}$, which represent the $\mathrm{sp}^{2}$ and $\mathrm{sp}^{3}$ hybridized systems, respectively.

During the last few years, several different theoretical methods have been used to study catalytic reactions on solid surfaces. These methods essentially fall into three major categories: finite cluster quantum chemistry, embedded cluster methods and periodic slab density functional theory methods. The advantages and disadvantages of all of these methods have already been thoroughly discussed in the literature. For a recent survey see for example Ref. [30]. Metal clusters have since long been one of the most common approaches used to model metal surfaces. This approach is a straightforward consequence of the idea that adsorption is a local phenomenon. Quantum chemical research on clusters has become very fruitful, especially due to advances in the development of density functional theory techniques and the incorporation of gradient correction terms to the exchange-correlation energy. The cluster model approach will be used along this work.

The aim of the present study is to compile theoretical results for the adsorption of ethylene on the di- $\sigma$ and $\pi$-top adsorption sites on the (100) surfaces of platinum, palladium and nickel under the same conditions, in terms of methodology, cluster size and shape and basis sets, in order to compare and understand the trends in the adsorption of this species on these three metal surfaces.

This paper is organized as follows. In Section 2 we describe the details of the computational method and the metal clusters used to describe the metal surface. In Section 3, we report and discuss the results obtained for the adsorption of the ethylene molecule on the di- $\sigma$ and $\pi$ sites on the (100) surfaces of platinum, palladium and nickel. Some general conclusions are summarized in Section 4. 

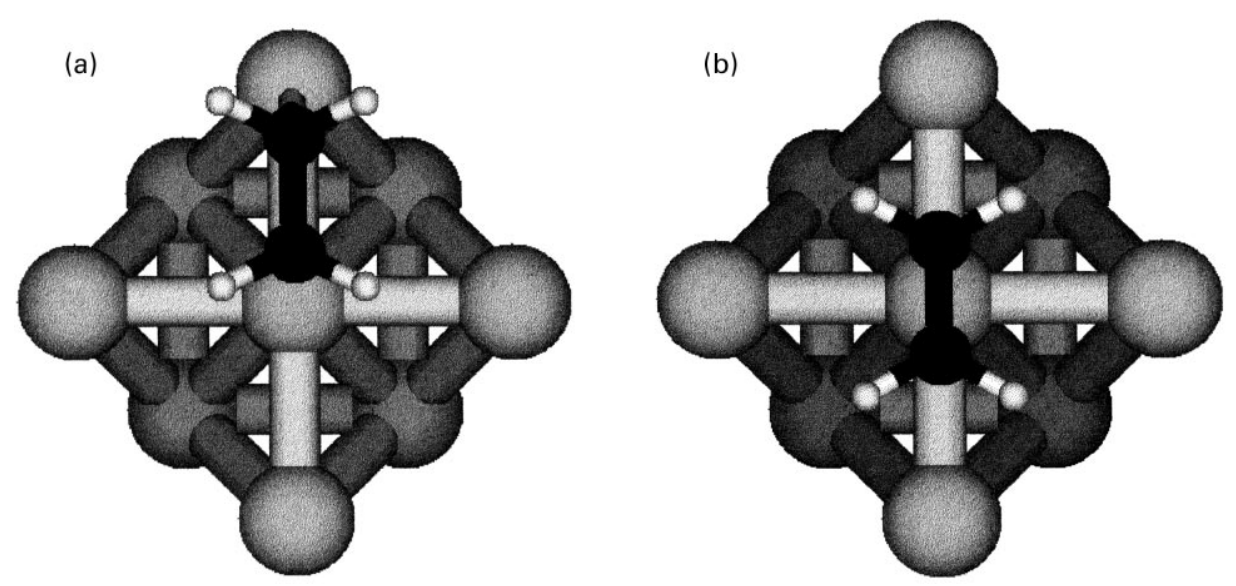

Fig. 1. Top views of the two adsorption modes studied on the (100) surfaces of platinum, palladium and nickel. The three metal surfaces were modeled by a two-layer $\mathrm{M}_{9}(5,4)$ cluster. In these clusters all the metal atoms are described by the large LANL2DZ basis set: (a) di- $\sigma$ adsorption mode; and (b) $\pi$ adsorption mode.

\section{Method}

In the present work, the interaction of the ethylene molecule with the (100) surfaces of platinum, palladium and nickel is studied using the cluster model approach. All these metals have a face centered cubic crystal structure. The platinum, palladium and nickel surfaces are modeled by a two-layer $\mathrm{M}_{9}(5,4)$ cluster of $C_{4 V}$ symmetry, as shown in Fig. 1, where the numbers inside brackets indicate the number of metal atoms in the first and second layer, respectively. It must be stressed that in all these clusters, all the metal atoms are described by the large LANL2DZ basis set. This basis set treats the outer 18 electrons of platinum, palladium and nickel atoms with a double zeta basis set and treats all the remaining electrons with the effective core potential of Hay and Wadt [31]. The non-metallic atoms $(\mathrm{C}$ and $\mathrm{H})$ are described by the $6-31 \mathrm{G}^{* *}$ basis set of double zeta quality with $p$ polarization functions in hydrogen atoms and d polarization functions in carbon atoms. In all the clusters, the nearest-neighbor distances were taken from the bulk and are $2.77483 \AA$ for platinum, $2.75114 \AA$ for palladium and $2.49184 \AA$ for nickel. These clusters form compact sections of the corresponding ideal surfaces. There are many examples in the literature where small cluster models, often smaller than those used in this study have proved very useful in the study of the adsorption of individual species and have provided accurate descriptions of adsorbate structures, vibrations and chemisorption energies. The use of larger clusters in the present work would be inaccessible given the number of valence electrons explicitly considered, the basis set quality and the computing power available in this study.

The density functional theory was used to obtain the geometries, adsorption energies and frequencies for the ethylene molecule adsorbed in the $\pi$-top and di- $\sigma$ adsorption modes on the (100) surfaces of all the transition-metals cited above. The B3LYP hybrid method proposed by Becke [32] and included in the GAUSSIAN 98 [33] package was used. This method includes a mixture of Hartree-Fock and DFT exchange terms associated with the gradient corrected correlation functional of Lee et al. [34]. In all the calculations the metal cluster geometry was kept frozen.

In the study of the di- $\sigma$ adsorption mode, the adsorbate was placed with its CC axis parallel to the surface and with its carbon atoms bridging the nearest-neighbor metal atoms at the surface (overall symmetry: $C_{s}$ ), see Fig. 1a. In the study of the $\pi$-top adsorption mode, the overall system 'adsorbate/metal substrate' was forced to have $C_{2 V}$ symmetry, in order to reduce the size of the calculation, see Fig. $1 b$.

The determination of the adsorption energies has been one of the most critical and controversial aspects of the cluster modeling of surfaces and several 
Table 1

Optimized geometry and $\mathrm{C}-\mathrm{C}$ MOP for the free $\mathrm{C}_{2} \mathrm{H}_{4}$ molecule

\begin{tabular}{lcl}
\hline $\mathrm{C}_{2} \mathrm{H}_{4}$ & Theoretical values & Experimental values ${ }^{\mathrm{a}}$ \\
\hline Distance $(\mathrm{CC})(\AA)$ & 1.3306 & $1.337 \pm 0.003$ \\
Distance $(\mathrm{CH})(\AA)$ & 1.0868 & $1.086 \pm 0.003$ \\
Angle $(\mathrm{HCC})\left({ }^{\circ}\right)$ & 121.818 & $121.35 \pm 1$ \\
Angle $\left(\left(\mathrm{CH}_{2}\right)-\mathrm{C}\right)\left(^{\circ}\right)$ & 180.000 & 180.00 \\
$\mathrm{C}-\mathrm{C}(\mathrm{MOP})($ a.u. $)$ & 1.3682 & - \\
\hline
\end{tabular}

${ }^{a}$ Ref. [37].

different ways have already been proposed in order to improve their calculation, for example, the bond preparation approach [35]. However, these alternative ways are not always straightforward and are often ambiguous. So in our calculation of the adsorption energies, the energies of the lowest spin multiplicity bare clusters and the energy of the lowest spin multiplicity gas phase ethylene molecule have been used as reference. The cohesive energies of these bare clusters, i.e. $E\left(\mathrm{M}_{9}\right)-9\left(E \mathrm{M}_{1}\right) E \mathrm{M}_{1}$ being the energy of a single metal atom in its ground state, are $820 \mathrm{~kJ} \mathrm{~mol}^{-1}$ for nickel, $1153 \mathrm{~kJ} \mathrm{~mol}^{-1}$ for palladium and $1826 \mathrm{~kJ} \mathrm{~mol}^{-1}$ for platinum.

\section{Results and discussion}

\subsection{Free $\mathrm{C}_{2} \mathrm{H}_{4}$ molecule}

The free ethylene molecule was optimized at the B3LYP/6-31G** level. The computed geometry and $\mathrm{C}-\mathrm{C}$ Mulliken overlap population [36] are listed in Table 1 along with the corresponding experimental values [37]. Note that, we will always refer to the angle ' $\left(\mathrm{CH}_{2}\right)-\mathrm{C}$ ' as being the angle between the $\mathrm{HCH}$ plane and the $\mathrm{CC}$ bond. This is exemplified in Fig. 2. Vibrational frequency calculations were also performed and the results are shown in Table 2 along with the corresponding experimental values [38]. The

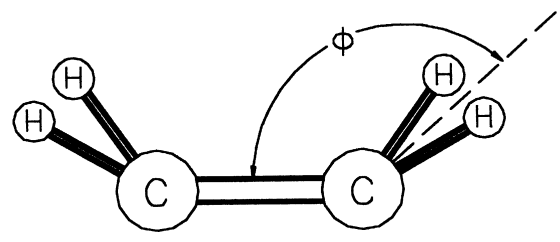

Fig. 2. The angle $\left(\mathrm{CH}_{2}\right)-\mathrm{C}$.
Table 2

Vibrational frequencies $\left(\mathrm{cm}^{-1}\right)$ of the free $\mathrm{C}_{2} \mathrm{H}_{4}$ molecule. Values inside brackets are scaled by a factor of 0.9614 (see Ref. [39])

\begin{tabular}{lcl}
\hline Mode & Theoretical values & Experimental values ${ }^{\mathrm{a}}$ \\
\hline$\nu_{10}, \rho\left(\mathrm{CH}_{2}\right)$ & $831(799)$ & $826(\mathrm{IR})$ \\
$\nu_{8}, \omega\left(\mathrm{CH}_{2}\right)$ & $961(924)$ & $940(\mathrm{R})$ \\
$\nu_{7}, \omega\left(\mathrm{CH}_{2}\right)$ & $976(938)$ & $949(\mathrm{IR})$ \\
$\nu_{4}, \tau\left(\mathrm{CH}_{2}\right)$ & $1069(1028)$ & Forbidden \\
$\nu_{6}, \rho\left(\mathrm{CH}_{2}\right)$ & $1240(1192)$ & $1222(\mathrm{R})$ \\
$\nu_{3}, \delta\left(\mathrm{CH}_{2}\right)$ & $1387(1333)$ & $1342(\mathrm{R})$ \\
$\nu_{12}, \delta\left(\mathrm{CH}_{2}\right)$ & $1482(1425)$ & $1444(\mathrm{IR})$ \\
$\nu_{2}, \nu(\mathrm{CC})$ & $1714(1648)$ & $1623(\mathrm{R})$ \\
$\nu_{11}, \nu_{\mathrm{s}}\left(\mathrm{CH}_{2}\right)$ & $3147(3025)$ & $2989(\mathrm{IR})$ \\
$\nu_{1}, \nu_{\mathrm{s}}\left(\mathrm{CH}_{2}\right)$ & $3162(3040)$ & $3026(\mathrm{R})$ \\
$\nu_{5}, \nu_{\mathrm{a}}\left(\mathrm{CH}_{2}\right)$ & $3223(3098)$ & $3103(\mathrm{R})$ \\
$\nu_{9}, \nu_{\mathrm{a}}\left(\mathrm{CH}_{2}\right)$ & $3248(3122)$ & $3105(\mathrm{IR})$ \\
\hline
\end{tabular}

${ }^{a}$ Ref. [38].

agreement between the theoretical results in Tables 1 and 2 and the corresponding experimental results is good.

\section{2. $\mathrm{C}_{2} \mathrm{H}_{4} / \mathrm{Pt}(100)$}

Table 3 summarizes the computed geometries, adsorption energies, Mulliken overlap populations (MOP) of some relevant bonds and total adsorbate charges obtained for the di- $\sigma$ and $\pi$ adsorption modes of the $\mathrm{C}_{2} \mathrm{H}_{4}$ molecule on a $\mathrm{Pt}(100)$ surface. Note that, the $\mathrm{C}_{2} \mathrm{H}_{4}$-surface distance will be defined as the perpendicular distance between the $\mathrm{CC}$ bond and a plane containing the nucleus of the metal atoms of the first layer.

The results show that the ethylene molecule binds very strongly on a $\operatorname{Pt}(100)$ surface and its geometric and electronic structure are highly perturbed by the adsorption process. The perpendicular $\mathrm{C}-\mathrm{Pt}$ surface distances are $1.9815 \AA$ for the di- $\sigma$ mode and $2.0813 \AA$ for the $\pi$ mode. Compared to the calculated value of the $\mathrm{CC}$ bond in the free ethylene molecule $(1.3306 \AA$ ) we find an elongation of the $\mathrm{CC}$ bond of $0.1594+(\mathrm{di}-\sigma)$ and $0.0906 \AA(\pi)$. The $\mathrm{H}-\mathrm{C}-\mathrm{H}$ plane is bent upward by $42.3^{\circ}$ (di- $\sigma$ ) and $22.0^{\circ}(\pi)$. These geometrical changes indicate a significant rehybridization of the carbon atoms from $\mathrm{sp}^{2}$ toward $\mathrm{sp}^{3}$, in particular in the di- $\sigma$ adsorption mode. The $\mathrm{C}-\mathrm{C}$ MOP dropped from 1.3682 (gas phase) to 0.6651 (di$\sigma)$ and $0.7075(\pi)$. The chemisorbed ethylene 
Table 3

Adsorption energies $\left(\mathrm{kJ} \mathrm{mol}^{-1}\right)$, optimized geometries, $\mathrm{C}-\mathrm{C}$ and $\mathrm{C}-\mathrm{Pt} \mathrm{MOP}$ and total adsorbate charges, $Q$, for $\mathrm{C}_{2} \mathrm{H}_{4}$ adsorbed on the di- $\sigma$ and top sites of the $\operatorname{Pt}(100)$ surface

\begin{tabular}{|c|c|c|}
\hline $\mathrm{C}_{2} \mathrm{H}_{4} / \mathrm{Pt}(100)$ & di- $\sigma$ adsorption & $\pi$-top adsorption \\
\hline Adsorption energy $\left(\mathrm{kJ} \mathrm{mol}^{-1}\right)$ & -223.8 & -149.5 \\
\hline Distance $\mathrm{C}_{2} \mathrm{H}_{4}$-surface $(\AA)$ & 1.9815 & 2.0813 \\
\hline Distance CC $(\AA)$ & 1.4900 & 1.4212 \\
\hline Distance $\mathrm{CH}(\AA)$ & 1.0937 & 1.0851 \\
\hline Angle $\mathrm{CCH}\left({ }^{\circ}\right)$ & 114.344 & 119.375 \\
\hline Angle $\left(\left(\mathrm{CH}_{2}\right)-\mathrm{C}\right)\left(^{\circ}\right)$ & 137.736 & 158.017 \\
\hline C-C MOP (a.u.) & 0.6651 & 0.7075 \\
\hline $\mathrm{C}-\mathrm{Pt}^{\mathrm{a}} \mathrm{MOP}$ (a.u.) & $0.6217 / 0.5271$ & $0.4034 / 0.4034$ \\
\hline$Q_{\text {adsorbate }}($ Mulliken) (a.u.) & +0.1314 & +0.3925 \\
\hline
\end{tabular}

${ }^{a}$ The two values refer to the MOP between each carbon atom and its nearest metal atom. Due to the shape of the cluster used to perform these calculations in the study of the di- $\sigma$ adsorption the $\mathrm{C}_{2} \mathrm{H}_{4} / \mathrm{Pt}_{9}$ system has $\mathrm{C}_{s}$ symmetry and so the carbon atoms have sligthly different electronic populations. In the study of the $\pi$ adsorption, the $\mathrm{C}_{2} \mathrm{H}_{4} / \mathrm{Pt}_{9}$ system has $C_{2 V}$ symmetry and the two carbon atoms have identical electronic populations.

molecule is positively charged on both adsorption modes, $+0.1314(\mathrm{di}-\sigma)$ and $+0.3925(\pi)$ and this indicates that there is a net transfer of electrons from the adsorbate molecule to the metal cluster and that in both adsorption modes the $\sigma$-donation is greater than the $\mathrm{d}-\pi^{*}$ back-donation. The results in Table 3 also show that the adsorption energy is much higher $\left(-223.8\right.$ versus $\left.-149.5 \mathrm{~kJ} \mathrm{~mol}^{-1}\right)$ when ethylene adsorbs on the di- $\sigma$ mode. This is in agreement with the experimental finding that when ethylene adsorbs on $\mathrm{Pt}(100)$ at low temperatures $(T \cong 100 \mathrm{~K})$ only di- $\sigma$ complexes are formed [20,21].

Vibrational frequencies have been calculated from the minima geometries for the two adsorption modes and the results are shown in Table 4. Note that for reasons of simplicity, we will always refer to the vibrational modes of the adsorbed ethylene molecule

Table 4

Calculated vibrational frequencies $\left(\mathrm{cm}^{-1}\right)$ for $\mathrm{C}_{2} \mathrm{H}_{4}$ adsorption on the di- $\sigma$ and $\pi$ adsorption modes on a $\operatorname{Pt}(100)$ surface

\begin{tabular}{lccc}
\hline $\mathrm{C}_{2} \mathrm{H}_{4} / \mathrm{Pt}(100)$ & di- $\sigma$ adsorption & $\pi$-top adsorption & Experimental $^{\mathrm{a}}$ \\
\hline$\nu_{\mathrm{s}}(\mathrm{C}-\mathrm{Pt})$ & 437 & 340 & 450 \\
$\nu_{4}, \tau(\mathrm{CH})$ & 803 & 902 & - \\
$\nu_{2}, \nu(\mathrm{CC})$ & 1027 & 1202 & 984 \\
$\nu_{7}, \omega\left(\mathrm{CH}_{2}\right)$ & 1062 & 979 & - \\
$\nu_{3}, \delta\left(\mathrm{CH}_{2}\right)$ & 1473 & 1517 & - \\
$\nu_{1}, \nu_{\mathrm{s}}\left(\mathrm{CH}_{2}\right)$ & 3062 & 3159 & 2936 \\
\hline
\end{tabular}

${ }^{\mathrm{a}}$ Ref. [20]. by the mode numbers derived for the free molecule. The $\nu(\mathrm{C}-\mathrm{Pt})$ stretching frequency is higher for adsorption on the di- $\sigma$ mode than on the $\pi$ mode indicating a stronger bond in the former case. The calculated vibrational frequencies for the di- $\sigma$ adsorption mode agree fairly well with the available experimental data [20] but the calculated values for the $\pi$ top adsorption mode differ significantly from the experimental data [20]. This strengthens the idea that on a $\operatorname{Pt}(100)$ surface, at low temperatures, the ethylene molecule adsorbs only as a di- $\sigma$ complex.

\section{3. $\mathrm{C}_{2} \mathrm{H}_{4} / \mathrm{Pd}(100)$}

Table 5 lists the results obtained for $\mathrm{C}_{2} \mathrm{H}_{4}$ adsorbed on a $\operatorname{Pd}(100)$ surface on the di- $\sigma$ and $\pi$ adsorption modes. In the only known experimental studies on the adsorption of $\mathrm{C}_{2} \mathrm{H}_{4}$ on a $\mathrm{Pd}(100)$ surface, at low temperatures, Stuve et al. [22,23] using TPRS and EELS concluded that both di- $\sigma$ and $\pi$-bonded forms are stable and coexist on this surface at $80 \mathrm{~K}$. However, according to the results shown in Table 5, the adsorption energy of the $\mathrm{C}_{2} \mathrm{H}_{4}$ molecule is larger on the di- $\sigma$ mode than on the $\pi$ mode by approximately $73 \mathrm{~kJ} \mathrm{~mol}^{-1}$. When adsorbed on the di- $\sigma$ mode, the perpendicular $\mathrm{C}-\mathrm{Pd}$ surface distance is $1.9651 \AA$, the CC distance is $1.4556 \AA$ and the $\mathrm{H}-\mathrm{C}-\mathrm{H}$ plane is bent upward by $35.8^{\circ}$. On this adsorption mode, the $\mathrm{CC}$ bond elongation is accompanied by a drop of the CC MOP from 1.3682 (gas 
Table 5

Adsorption energies $\left(\mathrm{kJ} \mathrm{mol}^{-1}\right.$ ), optimized geometries, $\mathrm{C}-\mathrm{C}$ and $\mathrm{C}-\mathrm{Pd} \mathrm{MOP}$ and total adsorbate charges, $Q$, for $\mathrm{C}_{2} \mathrm{H}_{4}$ adsorbed on the shortbridge and top sites of the $\operatorname{Pd}(100)$ surface

\begin{tabular}{lcc}
\hline $\mathrm{C}_{2} \mathrm{H}_{4} / \mathrm{Pd}(100)$ & di- $\sigma$ adsorption & $\pi$-top adsorption \\
\hline Adsorption energy $\left(\mathrm{kJ} \mathrm{mol}^{-1}\right)$ & -81.0 & -32.2 \\
Distance $\mathrm{C}_{2} \mathrm{H}_{4}$-surface $(\AA)$ & 1.9651 & 2.0382 \\
Distance $\mathrm{CC}(\AA)$ & 1.4556 & 1.4126 \\
Distance $\mathrm{CH}(\AA)$ & 1.0942 & 1.0865 \\
Angle $\mathrm{CCH}\left({ }^{\circ}\right)$ & 116.240 & 119.863 \\
Angle $\left(\left(\mathrm{CH}_{2}\right)-\mathrm{C}\right)\left({ }^{\circ}\right)$ & 144.157 & 160.715 \\
$\mathrm{C}-\mathrm{C}$ MOP $($ a.u. $)$ & 0.7413 & 0.7571 \\
$\mathrm{C}-\mathrm{Pd}^{\text {a }} \mathrm{MOP}($ a.u. & $0.5508 / 0.4388$ & $0.3976 / 0.3976$ \\
$Q_{\text {adsorbate }}($ Mulliken) (a.u.) & +0.1954 & +0.3385 \\
\hline
\end{tabular}

a The two values refer to the MOP between each carbon atom and its nearest metal atom.

phase) to 0.7413 . The $\pi$-metal forward donation outweighs the metal-to- $\pi^{*}$ back-donation of electrons and so the adsorbed ethylene is positively charged (on both adsorption modes). As far as we know, no experimental geometric results are available for adsorption of $\mathrm{C}_{2} \mathrm{H}_{4}$ on $\mathrm{Pd}(100)$.

The calculated vibrational frequencies are listed in Table 6 . The agreement between the calculated results for both adsorption modes and the experimental results [22,23] is good. However, the agreement between both kind of results is better in the case of the di- $\sigma$ adsorption mode. In this particular case, the calculated values of some of the most relevant vibrational modes (namely the $\nu_{\mathrm{s}}(\mathrm{C}-\mathrm{Pd})$ and the $\nu_{2}(\mathrm{CC})$ ) are in excellent agreement with the available experimental results. This strengthens the idea that on a $\operatorname{Pd}(100)$ surface the ethylene molecule adsorbs preferentially on the di- $\sigma$ mode.

New experimental vibrational data seems highly desirable in order to gain greater insight into the

Table 6

Calculated vibrational frequencies $\left(\mathrm{cm}^{-1}\right)$ for $\mathrm{C}_{2} \mathrm{H}_{4}$ adsorption on the di- $\sigma$ and $\pi$ adsorption modes, on a $\operatorname{Pd}(100)$ surface

\begin{tabular}{lccc}
\hline $\mathrm{C}_{2} \mathrm{H}_{4} / \mathrm{Pd}(100)$ & di- $\sigma$ adsorption & $\pi$-top adsorption & Experimental $^{\mathrm{a}}$ \\
\hline$\nu_{\mathrm{s}}(\mathrm{C}-\mathrm{Pd})$ & 391 & 329 & 390 \\
$\nu_{4}, \tau\left(\mathrm{CH}_{2}\right)$ & 796 & 886 & - \\
$\nu_{7}, \omega\left(\mathrm{CH}_{2}\right)$ & 955 & 920 & 920 \\
$\nu_{2}, \nu(\mathrm{CC})$ & 1109 & 1210 & 1135 \\
$\nu_{3}, \delta\left(\mathrm{CH}_{2}\right)$ & 1483 & 1525 & 1455 \\
$\nu_{1}, \nu_{\mathrm{s}}\left(\mathrm{CH}_{2}\right)$ & 3056 & 3143 & 2980 \\
\hline
\end{tabular}

${ }^{\text {a }}$ Refs. [22,23]. details of the adsorption geometry of ethylene on $\operatorname{Pd}(100)$ and to determine if at $80 \mathrm{~K}$ the $\pi$-bonded form of adsorbed ethylene really exists.

\section{4. $\mathrm{C}_{2} \mathrm{H}_{4} / \mathrm{Ni}(100)$}

The optimized geometries, adsorption energies, C$\mathrm{C}$ and $\mathrm{C}-\mathrm{Ni} \mathrm{MOP}$ and total adsorbate Mulliken charges obtained for the di- $\sigma$ and $\pi$ adsorption modes of $\mathrm{C}_{2} \mathrm{H}_{4}$ on a $\mathrm{Ni}(100)$ surface are presented in Table 7. The calculated vibrational frequencies are listed in Table 8 along with some available experimental frequencies.

The system $\mathrm{C}_{2} \mathrm{H}_{4} / \mathrm{Ni}(100)$ has already been studied theoretically by $\mathrm{Xu}$ et al. [27]. These authors, using the $\mathrm{X} \alpha$ method and modeling the surface with a $\mathrm{Ni}_{5}$ cluster concluded that the electronic structure of the adsorbed ethylene molecule was similar on both adsorption modes.

Experimentally, some contradictory results have been obtained in the study of the adsorption of $\mathrm{C}_{2} \mathrm{H}_{4}$ on a $\mathrm{Ni}(100)$ surface and general agreement on the bonding mode of ethylene on $\mathrm{Ni}(100)$ still does not exist. Zaera and Hall [24], studied the adsorption of ethylene on Ni(100) using TPD, LID and HREELS. Based on their TPD and LID results, the authors concluded that ethylene chemisorbs strongly at low temperatures and decomposes upon crystal heating. However, on their HREELS study, they interpreted a peak at $1575 \mathrm{~cm}^{-1}$ as corresponding to the CC stretching mode and based on this they concluded that the geometry of the molecule was only slightly perturbed by the adsorption process. More recently, 
Table 7

Adsorption energies $\left(\mathrm{kJ} \mathrm{mol}^{-1}\right.$ ), optimized geometries, $\mathrm{C}-\mathrm{C}$ and $\mathrm{C}-\mathrm{Ni}$ MOP and total adsorbate Mulliken charges, $Q$, for $\mathrm{C}_{2} \mathrm{H}_{4}$ adsorbed on the di- $\sigma$ and $\pi$ adsorption modes, on a $\mathrm{Ni}(100)$ surface

\begin{tabular}{lcc}
\hline $\mathrm{C}_{2} \mathrm{H}_{4} / \mathrm{Ni}(100)$ & di- $\sigma$ adsorption & $\pi$-top adsorption \\
\hline Adsorption energy $\left(\mathrm{kJ} \mathrm{mol}^{-1}\right)$ & -170.2 & -79.0 \\
Distance $\mathrm{C}_{2} \mathrm{H}_{4}$-surface $(\AA)$ & 1.8689 & 1.9075 \\
Distance $\mathrm{CC}(\AA)$ & 1.4620 & 1.4340 \\
Distance $\mathrm{CH}(\AA)$ & 1.0954 & 1.0876 \\
Angle $\mathrm{CCH}\left({ }^{\circ}\right)$ & 116.404 & 118.497 \\
Angle $\left(\left(\mathrm{CH}_{2}\right)-\mathrm{C}\right)\left({ }^{\circ}\right)$ & 143.334 & 152.442 \\
$\mathrm{C}-\mathrm{C} \mathrm{MOP}($ a.u. & 0.6775 & 0.7486 \\
$\mathrm{C}-\mathrm{Ni}^{\mathrm{a}} \mathrm{MOP}($ a.u. & $0.6526 / 0.4349$ & $0.4361 / 0.4361$ \\
$Q_{\text {adsorbate }}($ Mulliken) (a.u.) & +0.0820 & +0.1864 \\
\hline
\end{tabular}

a The two values refer to the MOP between each carbon atom and its nearest metal atom.

Sheppard [40] reanalyzed the results of Zaera and Hall [24] and concluded that the bands at $1575 \mathrm{~cm}^{-1}$ were experimental artifacts (possibly arising from a small fraction of vinylidene species) and that the CC stretching frequency had a much lower value $\left(\nu(\mathrm{CC}) \cong 1100 \mathrm{~cm}^{-1}\right)$. According to Sheppard [40], at low temperatures, the ethylene molecule chemisorbs on a $\mathrm{Ni}(100)$ surface in the di- $\sigma$ adsorption mode. Earlier results obtained by Lehwald et al. [25] had also supported the idea that the $\nu(\mathrm{CC})$ stretching mode had a value of about $1130 \mathrm{~cm}^{-1}$, and that the adsorbed molecule was highly distorted (relatively to its gas phase geometry).

The theoretical results obtained in the present work, strongly support the conclusions of Sheppard [40] and of Lehwald et al. [25]. The results in Table 7 show that the molecule binds strongly on a $\mathrm{Ni}(100)$ surface, the geometry and the electronic structure of the molecule are highly perturbed by the adsorption process and the

Table 8

Calculated vibrational frequencies $\left(\mathrm{cm}^{-1}\right)$ for $\mathrm{C}_{2} \mathrm{H}_{4}$ adsorption on the di- $\sigma$ and $\pi$ adsorption modes, on a $\mathrm{Ni}(100)$ surface

\begin{tabular}{lccr}
\hline $\mathrm{C}_{2} \mathrm{H}_{4} / \mathrm{Ni}(100)$ & di- $\sigma$ adsorption & $\pi$ adsorption & Experimental \\
\hline$\nu_{\mathrm{s}}(\mathrm{C}-\mathrm{Ni})$ & 388 & 284 & $350^{\mathrm{a}}$ \\
$\nu_{10}, \rho\left(\mathrm{CH}_{2}\right)$ & 885 & 847 & $840^{\mathrm{a}}$ \\
$\nu_{7}, \omega\left(\mathrm{CH}_{2}\right)$ & 890 & 833 & - \\
$\nu_{2}, \nu(\mathrm{CC})$ & 1090 & 1146 & $1130^{\mathrm{b}}$ \\
$\nu_{3}, \delta\left(\mathrm{CH}_{2}\right)$ & 1476 & 1501 & $1390^{\mathrm{b}}, 1385^{\mathrm{a}}$ \\
$\nu_{1}, \nu_{\mathrm{s}}\left(\mathrm{CH}_{2}\right)$ & 3042 & 3124 & $3010^{\mathrm{b}}, 3000^{\mathrm{a}}$ \\
\hline
\end{tabular}

\footnotetext{
${ }^{a}$ Ref. [24].
}

b Ref. [25]. di- $\sigma$ adsorption mode is more stable than the $\pi$ mode by approximately $91 \mathrm{~kJ} \mathrm{~mol}^{-1}$. The calculated CC bond length for the di- $\sigma$ mode, $1.46 \AA$, is identical to the experimental value determined by NEXAFS [26]. An analysis of the electronic structure shows that on both adsorption complexes the degree of the $\sigma$-donation is superior to that of the $\mathrm{d}-\pi^{*}$ backdonation. This same conclusion was obtained by $\mathrm{Xu}$ et al. [27] on their X $\alpha$ study. The observed net flow of electrons from the adsorbate to the surface is responsible for the formation of the $\mathrm{Ni}-\mathrm{C}$ bonds and for the lengthening and weakening of the $\mathrm{CC}$ bond. The lengthening of the $\mathrm{CC}$ bond is accompanied by a drop of the CC MOP from 1.3682 (gas phase) to $0.6775(\mathrm{di}-\sigma)$ and $0.7486(\pi)$.

The results in Table 8 show that the $\nu(\mathrm{CC})$ stretching mode has a value of about $1100 \mathrm{~cm}^{-1}$ which is in excellent agreement with the conclusions of Sheppard [40] and Lehwald et al. [25]. The agreement between the other available experimental frequencies and the theoretical results is also good.

\section{Conclusions}

In this work, we have studied the adsorption of ethylene on the (100) surfaces of platinum, palladium and nickel using a cluster with 9 metal atoms to model the surfaces. Despite the limited size of the clusters, some very interesting features of the systems 'adsorbate/metal surfaces' were determined, namely adsorbate geometries, adsorption energies and vibrational frequencies. According to our results, the adsorption 
energy of the ethylene molecule on a metallic surface depends strongly on the electronic structure of that surface and on the adsorption site.

The results show that, upon adsorption the degree of distortion of the ethylene molecule (relatively to its gas phase geometry), as well as the binding strength to the metal surface increases in the order $\mathrm{Pd} \rightarrow \mathrm{Ni} \rightarrow \mathrm{Pt}$. These results are in agreement with EELS results which showed that ethylene is more strongly bound and more distorted on $\mathrm{Ni}(111)$ and $\mathrm{Pt}(111)$ than on $\operatorname{Pd}(111)$ [5].

Our calculations also support the picture already suggested by several experimental studies of a significantly distorted adsorbate on the three metal surfaces: there is a lengthening of the $\mathrm{CC}$ bond and a rehybridization of the carbon atoms from $\mathrm{sp}^{2}$ towards $\mathrm{sp}^{3}$. On these three surfaces, the $\sigma$-donation is stronger than the $d-\pi^{*}$ back-donation leading to positively charged species on the surface. The results obtained also show that on platinum, palladium and nickel (100) surfaces, the ethylene molecule adsorbs preferentially on the di$\sigma$ mode. This conclusion is based not only on the adsorption energies (whose calculation is known to be the major problem of the cluster model approach) but also on a comparison between the calculated vibrational frequencies and the available experimental results.

Despite the general good agreement between the theoretical results obtained in the present work and the available experimental results, it must be noted that it is not unquestionable that a piece of metal can be correctly described using a molecular orbital approach. Besides, due to the problem of the dangling bonds (inherent to the cluster model approach), the 9 atom clusters (without embedding) used in the present work cannot give a very accurate description of the corresponding metallic surfaces. With regard to the calculation of the adsorption energies, we know that our method is not unambiguous. However, as we have already mentioned, there is a qualitative correspondence between the degree of distortion of the ethylene molecule (relatively to its gas phase geometry) and the corresponding calculated binding energy to the metal surface. So, it is our belief that any improvement of the reference energies for the various $M_{9}$ systems would not change our conclusions for the qualitative comparison of the binding energies. It may be said that the results presented in this work support the usefulness of the cluster model approach in the study of chemical processes on solid surfaces.

\section{Acknowledgements}

Financial support from the Fundação para a Ciência e Tecnologia (Lisbon) and project PRAXIS/PCEX/ C/QUI/61/96 is acknowledged. CGPMB thanks PRAXIS for a scholarship (BM/14665/97).

\section{References}

[1] A.M. Baro, S. Lehwald, H. Ibach, J. Electron Spectrosc. Relat. Phenom. (1980) 215.

[2] H. Steininger, H. Ibach, S. Lehwald, Surf. Sci. 117 (1982) 685.

[3] R.J. Koestner, J. Stöhr, J.L. Gland, J.A. Horsley, Chem. Phys. Lett. 105 (1984) 332.

[4] E. Yagasaki, R.I. Masel, Surf. Sci. 222 (1989) 430.

[5] J.A. Gates, L.L. Kesmodel, Surf. Sci. 120 (1982) L461.

[6] L.P. Wang, W.T. Tysoe, R.M. Ormerod, R.M. Lambert, H. Hoffmann, F. Zaera, J. Phys. Chem. 94 (1990) 4236.

[7] M. Nishijima, J. Yoshinobu, T. Sekitani, M. Onchi, J. Chem. Phys. 90 (1989) 5114.

[8] W.T. Tysoe, G.L. Nyberg, R.M. Lambert, J. Phys. Chem. 88 (1984) 1960.

[9] U. Gutdeutsch, U. Birkenheuer, E. Bertel, J. Cramer, J.C. Boettger, N. Rösch, Surf. Sci. 345 (1996) 331.

[10] J.A. Stroscio, S.R. Bare, W. Ho, Surf. Sci. 148 (1984) 499.

[11] T.K. Sham, R.G. Carr, J. Chem. Phys. 84 (1986) 4091.

[12] S. Bao, Ph. Hofmann, K-M. Schindler, V. Fritzsche, A.M. Bradshaw, D.P. Woodruff, C. Casado, M.C. Asensio, J. Phys.: Condens. Matter 6 (1994) L93.

[13] E. Cooper, R. Raval, Surf. Sci. 331-333 (1995) 94.

[14] V. Maurice, C. Minot, Langmuir 5 (1989) 734.

[15] Q. Ge, D.A. King, J. Chem. Phys. 110 (1999) 4699.

[16] R.M. Watwe, B.E. Spiewak, R.D. Cortright, J.A. Dumesic, J. Catal. 180 (1998) 184.

[17] J.F. Paul, P. Sautet, J. Phys. Chem. 98 (1994) 10,906.

[18] A. Fahmi, R.A. van Santen, Surf. Sci. 371 (1997) 53.

[19] Qi Minglong, C. Barbier, R. Subra, J. Mol. Catal. 57 (1989) 165.

[20] G.H. Hatzikos, R.I. Masel, Surf. Sci. 185 (1987) 479.

[21] G.H. Hatzikos, R.I. Masel, in: J.W. Ward (Ed.), Catalysis, 1987, Elsevier, Amsterdam, 1988, p. 883.

[22] E.M. Stuve, R.J. Madix, J. Phys. Chem. 89 (1985) 105.

[23] E.M. Stuve, R.J. Madix, C.R. Brundle, Surf. Sci. 152-153 (1985) 532.

[24] F. Zaera, R.B. Hall, Surf. Sci. 180 (1987) 1.

[25] S. Lehwald, H. Ibach, H. Steininger, Surf. Sci. 117 (1982) 342.

[26] F. Zaera, D.A. Fischer, R.G. Carr, J.L. Gland, J. Chem. Phys. 89 (1988) 5335.

[27] X. Xu, N.Q. Wang, Q.E. Zhang, J. Mol. Struct. 247 (1991) 93. 
[28] J. Chatt, L.A. Duncanson, J. Chem. Soc. (1953) 2939.

[29] M. Dewar, Bull. Soc. Chim. Fr. 18 (1951) C79.

[30] C. Minot, A. Markovits, J. Mol. Struct. (Theochem) 424 (1998) 119.

[31] P.J. Hay, W.R. Wadt, J. Chem. Phys. 82 (1985) 270.

[32] A.D. Becke, J. Chem. Phys. 98 (1993) 5648.

[33] M.J. Frisch, G.W. Trucks, H.B. Schlegel, G.E. Scuseria, M.A. Robb, J.R. Cheeseman, V.G. Zakrzewski, J.A. Montgomery, R.E. Stratmann, J.C. Burant, S. Dapprich, J.M. Millam, A.D. Daniels, K.N. Kudin, M.C. Strain, O. Farkas, J. Tomasi, V. Barone, M. Cossi, R. Cammi, B.
Mennucci, gaussian 98, Revision. A1, Gaussian, Inc., Pittsburgh, PA, 1998.

[34] C. Lee, W. Yang, R.G. Parr, Phys. Rev. B 37 (1980) 785.

[35] L. Triguero, L.G.M. Pettersson, B. Minaev, H. Agren, J. Chem. Phys. 108 (1998) 1193.

[36] R.S. Mulliken, J. Chem. Phys. 2 (1954) 782.

[37] H.C. Allen, E.K. Plyler, J. Am. Chem. Soc. 80 (1958) 2673.

[38] D. Van Lerberghe, I.J. Wright, J.L. Duncan, J. Mol. Spectrosc. 42 (1972) 251.

[39] A.P. Scott, L. Radom, J. Phys. Chem. 100 (1996) 16502.

[40] N. Sheppard, Annu. Rev. Phys. Chem. 39 (1988) 589. 